\title{
LA FIGURA DEL EMBRIÓN HUMANO EN LOS DEBATES ACTUALES DE LA ANTROPOLOGÍA DEL PARENTESCO: INDIVIDUO, MUNDO RELACIONAL Y COSMOLOGIA
}

\author{
The Human Embryo Figure in Current Debates on the Anthropology of Kinship:
} Individual, Relational World and Cosmology

\section{ALEJANDRO BILBAO* \& ENRIC PORQUERES**}

Fecha de recepción: 11 de noviembre de 2020 - Fecha de aprobación: 20 de marzo de 2021

In memoriam a Enric Porqueres (1962-2018)

\section{Resumen}

Tomando en cuenta el estatus concedido al embrión humano al interior de los estudios contemporáneos de la antropología del parentesco, el presente artículo aborda tres áreas fundamentales de indagación. En primer lugar, se analizan las representaciones que el mundo actual esboza en lo relativo a la figura del embrión a partir de la observación de la relación que estas representaciones guardan con la idea de individuo construida por las sociedades neoliberales. En segundo lugar, se observa la manera en que la vida embrionaria y fetal se esboza para reconsiderar las oposiciones clásicas realizadas por la antropología entre sociedades relacionales y sociedades conformadas por individuos. En tercer lugar, se evidencia la relevancia que posee la dimensión cosmológica y trascendental para comprender de un modo no naturalizado la existencia social de la persona humana, relativizando de esta manera la distinción entre sociedades relacionales y sociedades de individuos.

Palabras clave: antropología del parentesco; cosmología; ontogénesis; embrión; azar.

\begin{abstract}
Considering the status given to the human embryo within the sexual reproduction techniques, and the contemporary studies on the anthropology of parentage, this article addresses three fundamental research areas. First, it analyzes the constructs and representations that the contemporary world outlines regarding the human embryo figure, particularly highlighting the relationship between these representations and the idea of the individual, constructed by neoliberal societies. Second, it aims to observe the ways offered by the embryonic and fetal lives to reconsider the oppositions established by anthropology in a disciplinary manner, to make a distinction between relational societies and societies structured by individuals. Third, it shows the importance of the cosmological and transcendent dimension to understand, in a non-naturalized manner, the acquisition of societal ways of existence of the individuals.
\end{abstract}

Keywords: kinship anthropology; cosmology; ontogenesis; embryo; randomness.

* Dr. en Ciencias Humanas y Clínicas. Académico Instituto de Neurociencias Clínicas, Facultad de Medicina, Universidad Austral de Chile. Artículo enmarcado en el proyecto: "Individuación del embrión humano en la época de las biotecnologías reproductivas", investigación financiada por el programa ECOS-CONICYT (C14H02). Investigador responsable: Dr.

Alejandro Bilbao. Correo-e: manuel.bilbao@uach.cl

${ }^{*}$ Dr. en Antropología y Ciencias Históricas. Director de Estudios del Laboratoire d'Anthropologie des Institutions et des Organisations Sociales, École des Hautes Études en Sciences Sociales de Paris (EHESS). 


\section{Introducción}

Desde los orígenes de la disciplina antropológica, la naturaleza de los lazos de parentesco ha suscitado un vivo interés entre los antropólogos. En función de las posiciones teóricas de los autores, el campo de estudios sobre el parentesco se ha visto consagrado a contenidos diversos, a menudo contrapuestos. De un modo relativamente reciente, Marshall Sahlins (2013) ha definido el parentesco como "una red relacional entre personas y entre grupos de personas que se reconocen solidarias de su existencia en el mundo" (p. 29). Subrayando que "el parentesco no debe ser confundido con la biología" (p. 30), Sahlins se inscribe en toda una tradición de antropólogos que, apelando a las enseñanzas de Durkheim, muestran la irreductibilidad de los hechos del parentesco a algún fundamento de orden biológico y universal. En las páginas que siguen, se matizan, entre otros aspectos, los propósitos de Marshall Sahlins, pero también las referencias a la biología, ciencia occidental que, al consolidarse como tal únicamente a partir de fines del siglo XIX, difícilmente puede constituir la base angular de las teorías del parentesco en contextos no occidentales.

Sin embargo, es preciso señalar que nuestras representaciones biológicas o genéticas, y el conjunto de los sistemas de parentesco, se fundan en la referencia a un cuerpo relacional que, de este modo, se erige como horizonte infranqueable para concebir lo que es finalmente el parentesco. Las explicaciones nativas de la prohibición del incesto, o incluso las justificaciones de las uniones entre los más cercanos, como lo muestran los estudios de Levy sobre los mazdeístas que practican el xwedodah (2013), otorgan siempre un lugar crucial a los argu- mentos corporales. Es por estos argumentos que se explica la distancia necesaria o incluso la necesidad de la proximidad máxima de los cuerpos en la sexualidad. Aunque el incesto no pueda ser reducido a las relaciones expresadas a través del cuerpo y su lenguaje -como nos lo recuerdan perfectamente las prohibiciones en el caso del parentesco espiritual-, este se refiere siempre a unos vectores de transmisión identitaria que, no siendo necesariamente biológicos, no son, empero, menos corporales.

Émile Durkheim (2001), participante activo en los debates de su época sobre el totemismo, había comprendido perfectamente que, aunque la biología no diera cuenta de los hechos del parentesco, este se arraigaba siempre en cuerpos y genealogías. Es por esta vía que toda una serie de predicados relativos a la idea de orden, no solo de los grupos de personas que se reconocen emparentadas entre ellas, sino también de la constitución del cosmos y de sus partes, encuentra legitimidad y eficacia. La toma en consideración de los medios rituales de fabricación de la persona emparentada, al igual que la atención que estos medios suscitan en los juegos de correspondencias entre el cuerpo emparentado y la constitución de un todo cósmico, hacen de los autores citados los predecesores de ciertas investigaciones críticas de la razón genealógica. Durante el siglo XX, esta concepción y orientación de trabajo delimitó significativamente los estudios relativos al parentesco elaborados durante las décadas de 1960-1970. Aunque no existan referencias explícitas respecto de la implicancia de esta concepción en los debates antropológicos más recientes, las propuestas teóricas realizadas por Rodney Needham (1973) y Françoise Héritier (2012) retoman algunos de estos aspectos. Ambos autores reclaman el descentramiento 
de los esquemas genealógicos utilizados con frecuencia por los estudios del parentesco con el fin de producir análisis comparativos que puedan sortear la compleja deriva etnocentrista. Tanto Needham como Héritier impulsan una vigilancia epistemológica consistente con miras a restituir los campos semánticos de las nociones y los conceptos identificados y vinculados al parentesco. Los temblores o las sequías derivadas de los incestos, al igual que las equivalencias establecidas entre matrimonio y emergencia del mundo en muchos sistemas de intercambio generalizado, aparecen, de este modo, como objetos de una antropología del parentesco en franca ruptura con el formalismo genealógico.

Desde nuestro punto de vista, la toma en consideración de estos desarrollos, del mismo modo que el diálogo con algunas de las propuestas teóricas de la antropología clásica, ofrece un margen importante para el análisis. Sin duda que este ejercicio de reflexión permite construir de mejor modo los objetos de trabajo de la disciplina antropológica, inserta en un mundo globalizado y altamente tecnológico, sin por ello aislar los contextos culturalmente próximos a las realidades abordadas con mayor frecuencia por los antropólogos. El estatus y la evolución del ser in utero es, en este sentido, ilustrador: inserto en el parentesco y en la definición de la humanidad, el embrión de reproducción médicamente asistida nos aproxima a las dimensiones cosmológicas del cuerpo del parentesco, lo que permite, a su vez, reconsiderar las elaboraciones que la antropología esgrime para pensar la idea de individuo. Al mismo tiempo, este ser in utero consolida un material heurístico de relevancia para considerar las definiciones y oposiciones que se han elaborado para distinguir entre sociedades relacionales y sociedades conformadas por individuos.

\section{El embrión: un cuerpo transcendente}

En una síntesis importante relativa al parentesco y sus metamorfosis, Maurice Godelier afirma que "en ninguna parte, un hombre y una mujer son suficientes para generar un niño" (2004, p. 325). Como lo muestran los numerosos ejemplos proporcionados por el autor, "en todas partes son necesarias unas entidades que transcienden la corporeidad del parentesco para formar un ser humano de pleno derecho y digno de la vida que porta" (p. 339). Así nos es descrito cómo, en el conjunto de las culturas humanas, las entidades metafísicas se inmiscuyen tan sistemáticamente en los cuerpos del parentesco que estos se transforman, lo que permite observar su proceso de mutación en futuros interlocutores humanos:

\footnotetext{
Las representaciones del cuerpo son ideas, y las ideas adquieren su origen más allá del lenguaje, en el pensamiento (consciente pero también inconsciente). El sentido de este pensamiento no es expresión de un pensamiento vacío o reducido a estructuras formales. Es obra de un pensamiento volcado hacia las realidades sociales y cósmicas, que está menos preocupado de expresar estas realidades que de organizarlas y producirlas. (Godelier, 2004, p. 343)
}

Sin embargo, en el contexto occidental contemporáneo, la afirmación de Godelier parece no valer. Las descripciones de los antropólogos en estos contextos otorgan poco espacio a lo transcendente. Es de esta forma que uno podría preguntarse -con toda legitimidad-si en verdad en ninguna parte un hombre y una mujer son suficientes para hacer un niño. En nuestra opinión, la aceptación de este postulado viene a reforzar una vieja distinción inscrita en la división disciplinaria que, en el seno de las ciencias sociales, ha establecido una barrera entre los contextos occidentales y el resto de las expe- 
riencias culturales del mundo -entre the West and the Rest-. Mientras que la mayor parte de las sociedades humanas estarían regidas por el parentesco (sociedades relacionales), las nuestras solo reconocerían a la familia como entidad nuclear (sociedad de individuos). Mientras que en otros lugares la persona es concebida como un ser relacional modelado desde el inicio por fracciones y aspectos de otras personas y de otras relaciones, el contexto tecnológico nos confrontaría a la existencia de individuos puros (Strathern, 2005). Un contraste como este debería ser revisado en sus fundamentos considerando los problemas que se suponen obran en ambas direcciones. Es conveniente, por ello, resaltar inicialmente las dimensiones relacionales y trascendentes del individuo contemporáneo, sin olvidar la observación que cabe ejercer respecto de las formas de subjetivación de otros marcos y áreas culturales.

La biología contemporánea describe la evolución de lo viviente sobre la tierra a partir de las primeras bacterias surgidas en nuestro planeta hace más de 3.5 mil millones de años (Gould, 2002). La estructura hereditaria, el ADN de estos primeros seres vivientes, constituye el fundamento de la aparición de todas las especies que han vivido sobre la tierra. Mutando de un modo permanente por las interacciones que mantiene con el medio ambiente, el ADN bacteriano constituye el telón de fondo de una gran cadena del ser, en el seno de la cual se expresa una relación genealógica que une a todos los seres vivientes. De esta forma, podría mencionarse que "el hombre se ve definido a través de lazos de parentesco que señalan su lugar particular en el mundo" (Bellah, 2011, p. 49). El azar de las mutaciones sobre este fondo hereditario común se encuentra en el origen de la especie humana, la cual mantiene importantes vínculos con otras formas de existencia. El carácter antes que nada azaroso de estas mutaciones muestra que la emergencia de especies cada vez más complejas no es necesariamente una señal de la tendencia hacia la complejidad en la evolución. Los estudios de Gould y Eldredge (1977) respaldan la idea de que estas mutaciones genotípicas son producto del azar, sin ser ellas necesariamente la expresión de ventajas evolutivas o producto de la complejidad asociada a las especies de un modo particular.

Los experimentos terapéuticos realizados en ciertos animales con la esperanza de poder aplicar los resultados a nivel humano dramatizan y fortalecen esta hipótesis, de ahora en adelante admitida por casi la totalidad de la comunidad científica. Ciertos aspectos de este relato evolucionista encuentran un eco significativo en la relación que el azar mantiene con el problema de la ontogénesis humana. El azar que se encuentra en el origen de nuestra existencia como especie reaparece en la definición de lo "humano" en el seno de la dimensión abierta por la ontogénesis. Cada etapa de transformación del embrión humano y del posterior feto recapitula otras formas de existencia, evidenciando con ello la continuidad de la filogénesis en el proceso de la ontogénesis. Estas tesis fueron observadas tempranamente por Haekel (2012) en su historia de la evolución humana.

En la actualidad, los debates sobre la clonación hacen aparecer, en todo su esplendor, la dimensión trascendente de la constitución corporal del ser humano. El principio de respeto relativo a las variadas formas de manifestación de la humanidad se encuentra presente en permanencia en los debates de la bioética. 
Es sobre la base de este respeto necesario que se condena la práctica de la clonación humana. Así, una ley francesa de 2004 describe la clonación como un "crimen contra la dignidad de la persona humana" y las declaraciones internacionales -como la declaración no vinculante de la ONU en 2005- consideran que las modalidades de la clonación son "incompatibles con la dignidad humana” (Pulman, 2005, pp. 435-436).

Cabe, empero, destacar que la preocupación por la dignidad de la persona humana no debe ser desvinculada del contexto profundamente individualista en el cual se asientan las sociedades occidentales contemporáneas. De manera sistemática, los estudios de Marilyn Strathern (1992) han evidenciado que estas inquietudes éticas no pueden ser desvinculadas del contexto político y social de las sociedades occidentales, lo que refleja el profundo vínculo que este contexto mantiene con la oposición a la clonación reproductiva. Que un bebé pueda ser la copia de otra persona aparece como una amenaza a todo nuestro sistema de valores, incluso para nuestro porvenir. Nuestra sociedad se caracteriza, en efecto, por un sistema de parentesco que -se supone- produce individuos irreductibles a la suma de las individualidades de sus padres. Este individualismo está articulado a una filosofía de la historia liberal propia de las sociedades nacidas de la Revolución industrial (Wallerstein, 2009; Dardot, 2010). Si se considera que la multiplicación de nuevos elementos en el mundo constituye la condición de posibilidad del progreso, entonces, limitar la novedad de los individuos considerados como portadores de este progreso significa, por fuerza, comprometer el futuro, el cual, en términos temporales, debe permanecer esencialmente abierto.
De manera significativa, la argumentación a propósito de la clonación es correlativa a una definición que hace de este ejercicio un atentado a la naturaleza y a su diversidad. Desde la década de 1960, a continuación de las declaraciones de los biólogos comprometidos en esta vía, el fantasma del eugenismo aparece en la reflexión sobre la bioética (Pulman, 2005). En el centro de la polémica se ubica la tensión entre el azar, que caracteriza a la reproducción natural, y la elección, que pone en peligro el libre curso de la naturaleza, fundamento mismo de la dignidad del hombre. Uno de los argumentos más relevantes para expresar las condiciones antagónicas de esta dignidad es que la significación de las relaciones familiares podría verse modificada por la clonación, ya que, como lo planteó en 2002 el Comité Norteamericano de Ética, bajo la dirección de Leon R. Kass, los "niños clonados serían los primeros seres humanos en los cuales todo el makeup genético sería seleccionado de antemano. Podrían ser considerados más como los productos de un proceso de fabricación que concebidos como unos 'regalos' que los padres estarían dispuestos a aceptar tal como son" (Kass, 2002, pp. 102-112).

La crisis de la aceptación incondicional de una progenie propia, concebida mayoritariamente en nuestra época como un aspecto esencial de la paternidad y la maternidad, revela la incidencia moral del carácter imprevisible de cada nuevo ser humano. Se subraya, de igual manera, que la clonación, contrariamente a la reproducción por FIV (fecundación in vitro), se diferencia de forma radical de la manera natural de engendrar a los hijos puesto que esta última garantiza la independencia genética relativa de los hijos respecto de sus padres luego de la composición, sometida al azar por medio del ADN de estos últimos. Se hace valer que, si uno solo de 
los padres transmite su información genética, el engendramiento se transforma en fabricación de su propia progenie.

Engendrar de forma voluntaria la copia de un adulto se diferencia, evidentemente, de tener gemelos. El primer tipo de engendramiento no es el resultado de la evolución azarosa del blastocito. De esta manera, la clonación aparece como la negación de la experiencia humana de la relación de parentesco y, al mismo tiempo, de la experiencia de la individualidad. Tal como lo declara el Consejo Americano de Bioética:

[...] al crear personas genéticamente nuevas, la reproducción sexual dota a todos los seres humanos del sentido de una identidad individual, y les asegura ocupar en este mundo un lugar que nunca ha pertenecido a otro. Nuestra identidad genética nueva simboliza y anuncia el carácter único, que no será nunca repetido [never-to-be-repeated] en cada vida humana. (Kass, 2002 p.103)

Desde luego, al igual que los biólogos, los miembros del Consejo de Bioética no afirman que la genética determina la identidad personal, sino que están completamente al tanto de su importancia simbólica. Por supuesto, nuestro makeup genético no fija, por sí mismo, nuestras identidades. Sin embargo, nuestra "unicidad" genética determina, de manera importante, el sentido de quiénes somos y la manera como nos consideramos. Es un emblema de independencia y de individualidad que nos dota de un sentido de la vida como posibilidad nunca-antes-realizada -"never-before-enacted-possibility"-. Es, en este sentido, que se puede hablar del probable sufrimiento moral de un bebé clonado: sometido a percibir su propia vida a la luz de la copia de la que precede. La dimensión simbólica de este presunto sufrimiento es, sin duda, central. Hace, empero, caso omiso del hecho de que la clonación comporta siempre la contribución del ADN mitocondrial del óvulo extirpado y de que el medio biológico del embarazo tiene, necesariamente, una incidencia en la expresión genética de la célula clonada.

La dicotomía establecida entre una reproducción fundada en el azar y otra sobre la elección de la persona -dicotomía que resuena en los debates actuales sobre la selección de embriones y sobre la aplicación del diagnóstico de preimplantación-ilustra con bastante claridad el elemento trascendente presente en la embriología contemporánea, tal como es abordada por los científicos y por las personas encargadas de reflexionar sobre la reproducción humana (Pulman, 2005). Es evidente que, en la actualidad, la materialidad o, más precisamente, la realidad informacional transmitida por el patrimonio genético de los padres -que, por otra parte, tal como nos lo enseña la nueva genética, pone a los humanos en relación con numerosas especies, presentes y desaparecidas- no es suficiente para definir a una persona. Está claro que, desde el inicio de su existencia, el ser humano está constituido por un azar trascendente, el mismo azar que está en el centro de los discursos científicos sobre la aparición del hombre en el curso de la evolución de las especies. Las expresiones y los símbolos de la unicidad de la persona ligados al principio del porvenir abierto de la humanidad parecen estar inscritos en el seno de nuestro conocimiento científico del ser humano, convirtiéndose en el eco de nuestros relatos sobre los orígenes.

\section{El embrión, base y núcleo de individuación}

Diversos autores han insistido en las correlaciones existentes entre los mitos de origen y 
los discursos sobre la embriogénesis (Bidou, 2001; Griaule, 1966; Dieterlen, 2000). Los arunta australianos, los samo de Burkina Faso, los tuaregs de Azawad, los macha andinos, así como los debates escolásticos alrededor de la fabricación del embrión han proporcionado los materiales que permiten ilustrar la articulación siempre presente entre, por una parte, el cuerpo del parentesco, sometido a las reglas de la sexualidad que se desarrollan in utero, y a menudo marcado por discontinuidades ontológicas, y, por otra parte, las instancias transcendentes indispensables para la fabricación de una nueva persona. Para existir como tal -así como lo ilustra el mundo contemporáneo-, junto a la importancia dada al azar en la combinación de las informaciones genéticas del progenitor y la progenitora, la persona necesita, en efecto, de algo más de lo que le aportan padre y madre. Este dato puede ser observado en las diversas etnografías desarrolladas en medio de África Occidental.

Este contexto de terreno, además de observar los paralelismos entre ontogénesis y filogénesis, ha podido constatar la presencia particularmente significativa de los sentidos cosmológicos que organizan la fabricación de un nuevo ser. Aludimos a aquello que la literatura antropológica refiere respecto de las nuevas tecnologías reproductivas (Franklin, 1993) como una particularidad de la modernidad tecnológica contemporánea: la fabricación de individuos poseedores de una dimensión moral desde la etapa embrionaria, es decir, el embrión como un individuo potencial. Las relaciones entre esta instancia y la noción de persona nos son presentadas de un modo central en el contexto tecnológico y urbano contemporáneo. Al abordar este tema, la etnografía muestra que no se debería excluir este tipo de relación en los contextos cultura- les menos cercanos. Al hablar del "yo" y de la utilización de pronombres personales, Marcel Mauss insistía, de un modo temprano, en que no podría existir un ser humano "que no haya tenido el sentido, no solamente de su cuerpo, sino también de su individualidad espiritual y corporal a la vez" (Mauss, 2012, p. 331). Las etnoembriologías de África Occidental dramatizan la inscripción de este yo constitutivo de la persona a través de ciertas escenas y relatos.

Para los samo del Alto Volta existe Mere, aquello que es inmortal en el hombre. El Mere es transmitido por Dios (la bunkunu) a la madre en el momento en que el cabello comienza a emerger en el feto. Mere no es un componente de la persona que sea exclusivo del hombre, pues como nyini su acción puede ser encontrada en plantas, en los grandes árboles, los cereales y los animales. Para los samo, la identidad es el resultado de los diversos componentes de la persona. Esta representación de la identidad humana nunca descansa en la delimitación de una frontera que distinga lo diverso y lo plural de la mismidad por medio de la cual el individuo afirma la identidad de sí. La identidad siempre es escrita en plural y en correspondencia con los continentes animales y vegetales, y manteniendo una relación con la dimensión trascendental. La ontogénesis del individuo no se limita a afirmar su unidad como ser, pues ese sentimiento alterna entre lo múltiple y lo Uno. A estos fines, el individuo no es la sola realidad a explicar para el modelo de individuación samo; las operaciones de individuación no progresan en el sentido de explicitar un principio de individuación anterior a las operaciones mismas que facultan lo individualizable. Las operaciones que fabrican la identidad se construyen en un espacio de intersección que define derechos y obligaciones imposibles de 
determinar en la consideración de un único principio rector.

En un texto consagrado al problema de la identidad en el pueblo samo, Françoise Héritier (2010) esboza una serie de argumentos que conducen a organizar la noción de individuo. Un individuo no se reduce jamás a las sustancias que lo componen, la identidad toma en cuenta todos los componentes de su ser tal y como estos son inventariados y articulados en el pensamiento de los miembros de esa sociedad. No se trata, entonces, solamente de sustancias corporales sino, también, del souffle, de la fuerza vital, del alma, de la sabana. Cuando Héritier se expresa respecto de las concepciones que los samo elaboran para comprender la fabricación de un nuevo ser, al mencionar que es Sisi, le souffle, quien penetra en el feto (en concordancia con el momento en que el embrión toma una forma humana), lo hace para intentar transmitir que, en las etnoteorías del proceso de procreación, el individuo está inscrito en una totalidad social y cósmica que desborda ampliamente las fronteras de su propia constitución de parentesco. $\mathrm{O}$, dicho de manera inversa, esas relaciones de parentesco no hacen más que reproducir, en un determinado nivel, la totalidad social y cósmica en la que la producción del individuo como una realidad única e irreproducible se hace efectiva.

Al interior de estas escenas y relatos, el destino prenatal es un tema recurrente en las etnografías que tratan sobre África Occidental. De Meyer Fortes a Stéphane Dugast, los autores que abordan esta área cultural han subrayado la importancia de una serie de elecciones operadas por el ser uterino, incluso por el ser preuterino, frente a entidades cosmológicas. Para los tallensi, el cielo y el sol son fundamentales para considerar estas elecciones (Fortes,
1987). También puede ser una divinidad la que cocina a los futuros humanos, como es el caso entre los gourmantché (Cartry, 2010). Pueden operar, igualmente, estas acciones uterinas el Sol, un ilusionista o un taumaturgo, como es el caso para los basar de Togo (Dugast, 2010). Sin embargo, en todos estos contextos africanos es necesario actuar sobre sí mismo para construir una vida digna, que conduzca a la realización plena de la personalidad propia. $Y$ esto, en el transcurso de una existencia individual concebida como transitoria y alterable (Izard, 1988). Así, entre los tallensi estudiados por Fortes, el yam, parte racional del ser que reside en el abdomen, asiento de la imaginación y de disposiciones morales, como la bondad y la gentileza, debe ser objeto de una vigilancia constante y creciente. Esto permite, justamente, hacer frente al azar, perturbador en potencia, que se deriva del yin, el destino pactado por las palabras frente al Cielo: Nuor Yin (Fortes, 1987).

Siempre proviniendo de un medio antenatal acuático, y conociendo a menudo las transformaciones ontológicas que hacen pasar al ser uterino por estadios diversos -sapo en los samo; pez en los dogon, los moossi (Bonnet, 1988) y los gourmantché (Cartry, 1968)-, el embrión se ve confrontado a elecciones, las cuales versan sobre la calidad de la existencia que quiere llevar una vez que haya llegado al mundo de los humanos extrauterinos. No obstante, el ser in utero puede ser imprudente o irracional en las opciones escogidas, de tal manera que una vida marcada por la pobreza, la infertilidad o la enfermedad podrían ser el resultado de una mala palabra prenatal. Por otro lado, aquello que es elegido por la "boca que habla" antes del nacimiento puede tener consecuencias sobre la vida de los descendientes, sobre todo en el caso de un destino prenatal femenino, asociado con 
frecuencia a la muerte prematura de los niños (Fortes, 1981). Las palabras son susceptibles de tener una incidencia sobre los ascendientes, ya que un hombre o una mujer pueden elegir no tener hermanos o hermanas menores, con lo que condicionan el ciclo reproductivo de sus padres. Todo se vuelve particularmente dramático por el hecho de que no se puede actuar sino a posteriori, pues el sujeto olvida, de manera inevitable, su elección prenatal. Es necesario, entonces, que los especialistas, los adivinos, restituyan el contexto de enunciación de estas palabras potencialmente nefastas. Una eventual negociación del contrato pasado por "el ser principiante" y las instancias transcendentes puede, únicamente por esta vía, tener lugar. En el mejor de los casos, los unos y los otros llegan a ver sus sufrimientos aliviados.

En el caso de las concepciones de los inuit referidas a la generación de un nuevo ser, estos consideran que es el padre quien fabrica, con su esperma, los huesos y el esqueleto del cuerpo del niño. La madre le provee la carne y la piel. El estado intrauterino concierne a un ser que es un feto y que no posee alma. Esto conduce a la consideración de que el feto en cuestión no es aún un ser humano, lo será el día de su nacimiento, cuando Sila, señor del universo, introduzca en su cuerpo una bola de aire que se convierte en el souffle del niño (su principio de vida). Estos procedimientos y operaciones de individuación que, progresivamente, fabrican lo que será su identidad no permiten que sea aún considerado un ser social. Este último acontecimiento dependerá de los nombres que reciba de sus padres en ceremonias destinadas a ese fin (Godelier, 2004).

\section{Conclusión}

Al igual que los debates sobre bioética, los contextos de África Occidental realizan una imputación de humanidad a través de la creación de un cierto nicho de subjetividad. La definición de un patrimonio genético único, garante de una vida humana digna de este nombre, al igual que la toma de palabra que compromete al ser prenatal después de que este ha abandonado las fases no humanas de su evolución, dramatizan, cada una a su manera, la entrada progresiva en la interlocución que vuelve posible la vida social. El individuo, a medida que emplea los pronombres personales y se considera responsable de sus actos, se inscribe, cada vez, en un sistema simbólico particular. Aun si en un principio las tesis de Godelier relativas a la generación de un nuevo ser podrían emerger distanciadas del mundo occidental, es preciso mencionar que el Occidente tecnológico de las reproducciones médicamente asistidas exige, también, algo más que un hombre y una mujer para hacer un nuevo humano digno de este nombre. En los dos contextos culturales considerados, los lazos sistemáticos con entidades trascendentes de diverso orden, ya sea el azar, o seres tales como el Sol u otras divinidades, vienen a establecer, en efecto, este basamento de humanidad común, a menudo olvidado por los antropólogos que abordan la noción de persona. Como puede apreciarse, el individuo llamado a actuar en el mundo se inserta por fuerza a través de modalidades que conviene registrar y elucidar en una cosmología. No es factible considerar la idea de un individuo que no transite por estos sistemas de representación concedidos a la vida humana. Que la noción de persona sea una categoría de trabajo 
de los estudios antropológicos muestra, fehacientemente, cuánto esta es dependiente de los sistemas de inscripción cultural que cada sociedad desarrolla en la valoración y la representación que es concedida a la noción de individuo.
Esta individuación no es nunca la consecuencia de un proceso que descarte la relevancia que cumple la dimensión transcendente o cosmológica de la persona.

\section{Referencias bibliográficas}

Bellah, R. (2011). Religion in human evolution: From the Paleolithic to the Axial Age. Cambridge, Massachusetts: The Belknap Press of Harvard University Press.

Bidou, P. (2001). Le mythe de Tapir Chamane: Essai d'anthropologie psychanalytique. París: Odile Jacob.

Bonnet, D. (1988). Corps biologique, corps social: Procréation et maladies de l'enfant en pays mossi, Burkina Fasso. Paris: OSRTOM.

Cartry, M. (1968). La calebasse de l'excision en pays gourmantché. Journal de la Société des Africanistes, 38, 189-226.

(2010). Du matériel divinatoire africain comme matière à

penser le destin. Incidence, 6, 61-77.

Dardot, P. (2010). La nouvelle raison du monde. Paris: La Découverte.

Dieterlen, G. (2000). Les dogon, notion de personne et mythe de la création. Paris : L'Harmattan.

Dugast, S. (2010). Figures voltaïques du destin prénatal: Du soleil personnel au conjoint de rivière chez les Bassar du Togo. Incidence, 6, 237-268.

Durkheim, É. (2001). Las reglas del método sociológico. México: Fondo de Cultura Económica.

Fortes, M. (1981). Oedipus and Job in West African religion. Nueva York: Octagon Books.

(1987). Essays on Tallensi religion. Cambridge: Cambridge

University Press.

Franklin, S. (1993). Making representations: The parliamentary debate on the human fertilization and embryology act (pp. 96-132). En Edwards, J. (Ed), Technologies of procreation. Manchester: Manchester University Press.

Godelier, M. (2004). Métamorphoses de la parenté. París: Fayard. Gould, S. (2002). The structure of evolutionary theory. Cambridge,
Massachusetts: Harvard University Press.

Gould, S. \& Eldredge, N. (1977). Punctuated equilibria: The tempo and mode of evolution reconsidered. Paleobiology, 3, 115-157.

Griaule, M. (1966). Dieu d'eau: Entretiens avec Ogotemmeli.

Paris: Fayard.

Haeckel, E. (2012). Anthropogénie, ou histoire de l'évolution humaine. Paris: Broché.

Héritier, F. (2010). L'identité Samo (pp. 51-72). En Lévi-Strauss, C. (Org.), L'identité. Paris: PUF. (2012). Les deux sœurs et leur mère: Anthropologie de l'inceste. Paris: Odile Jacob.

Izard, M. (1988). Préface (pp. 11-14). En Bonnet, D. (Org.), Corps biologique, corps social: Procréation et maladies de l'enfant en pays Mossi, Burkina Fasso. Paris: OSRTOM.

Kass, L. (2002). Human cloning and human dignity: The Report of the President's Council on Bioethics. En www.bioethics.gov

Levy, A. (2013). La prescription de l'inceste dans le mazdéisme. Incidence, 9, 139-166.

Mauss, M. (2012). Sociologie et anthropologie. Paris: PUF.

Needham, R. (1973). La parenté en question. Paris: Seuil.

Pulman, B. (2005). Les enjeux du clonage: Sociologie et bioéthique. Revue Française de Sociologie, 46, 413-442.

Sahlins, M. (2013). What kinship is-and is not. Chicago: Chicago University Press.

Strathern, M. (1992). After nature: English kinship in the late Twentieth Century. Cambridge: Cambridge University Press. (2005). Kinship, law and the unexpected: Relatives are always a surprise. Cambridge: Cambridge University Press.

Wallerstein, I. (2009). Comprendre le monde: Introduction à l'analyse des systèmes monde. Paris: La Découverte. 